\title{
AN ENGINEERING GEOLOGICAL ASSESSMENT USING TERRESTRIAL LASER SCANNING FOR THE STABILIZATION OF A VOLCANIC SLOPE IN SANTORINI ISLAND
}

\author{
Marinos V. ${ }^{1}$, Papathanassiou G.. ${ }^{1}$, Kaklis T. ${ }^{1}$, Prountzopoulos G. ${ }^{2}$, Asteriou \\ P. ${ }^{3}$, Pantazis G. ${ }^{4}$, Lambrou E. ${ }^{4}$, Grendas $\mathrm{N}^{1}{ }^{1}$ and Pavlides S. ${ }^{1}$ \\ ${ }^{1}$ Aristotle University of Thessaloniki, Department of Geology, 54124, Thessaloniki, Greece, \\ marinosv@geo.auth.gr,gpapatha@geo.auth.gr,kaklis@geo.auth.gr,ngrendas@geo.auth.gr, \\ pavlides@geo.auth.gr \\ ${ }^{2}$ Independent Geotechnical Engineering Consultant, 14564, Kifissia, Athens, Greece, \\ gproun@gmail.com \\ ${ }^{3}$ National Technical University of Athens, School of Civil Engineering, 15780, Zografou, Greece, \\ pasteriou@gmail.com \\ ${ }^{4}$ National Technical University of Athens, School of Rural and Surveying Engineering, 15780, \\ Zografou,, Athens, Greece, gpanta@central.ntua.gr, litsal@central.ntua.gr
}

\begin{abstract}
The present work presents an engineering geological assessment using terrestrial laser scanning for the study of stabilization of a rock slope in Santorini island that has suffered from several rock slide incidents. The use of LiDar laser scanning and focused surveying provided valuable data for the engineering geological zonation of the area and the rock block quantification for the stability analysis. In order to prevent failure and the accompanied consequences, slope stability analysis and various mitigation methods were examined based on the site's geological and geotechnical conditions, cost, local architecture restrictions and constructability.

Keywords: LiDar, slope stability analysis, rock fall hazard, support measures, ignimbrite.

\section{Пєрí $\eta \psi \eta$}

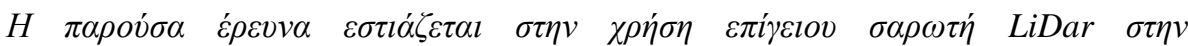

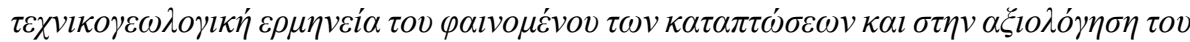

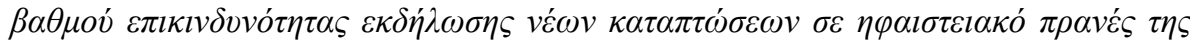

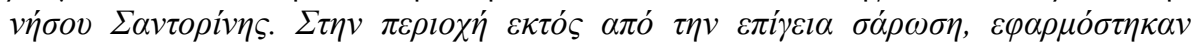

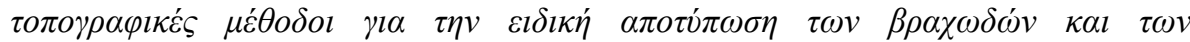

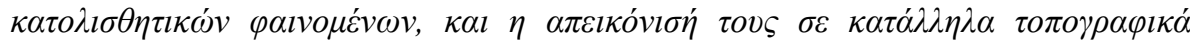

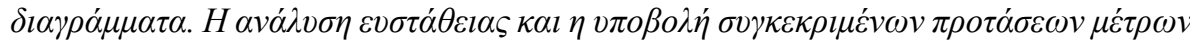

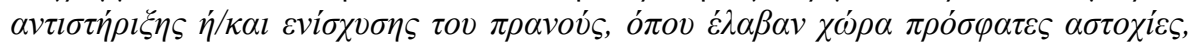

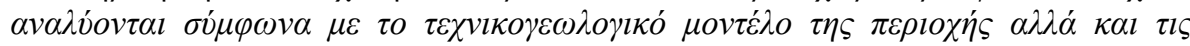

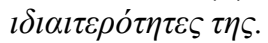

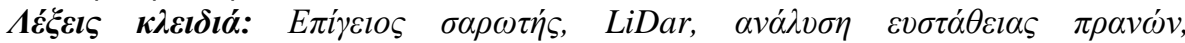

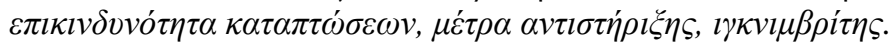




\section{Introduction}

The investigated area is located at the southern part of Santorini Island, east of the Akrotiri village, on a road that leads to the lone beach which can be found inside Santorini caldera (figure 1). Several rock fall incidents of significant magnitude have been recorded in the slope, especially after heavy rainfall. These rock falls have caused destructions on the road and its temporary disruption. These falls are not only confined along the road but can also reach the beach (figure 2) that is regularly used by the tourists and the fishermen. At the top of the slope, the presence of residences has increased the risk within the area.

The area is consisting of a typical heterogeneous series of volcanic rocks, i.e. competent and strong lava rocks overlying soft layers of tuffs, where differential erosion is favoured and significant joints are present. The morphology above the road is characterized by very steep slopes, up to $80^{\circ}$ and up to $15 \mathrm{~m}$ height. Below the road and until the beach, the slope presents also steep angles.

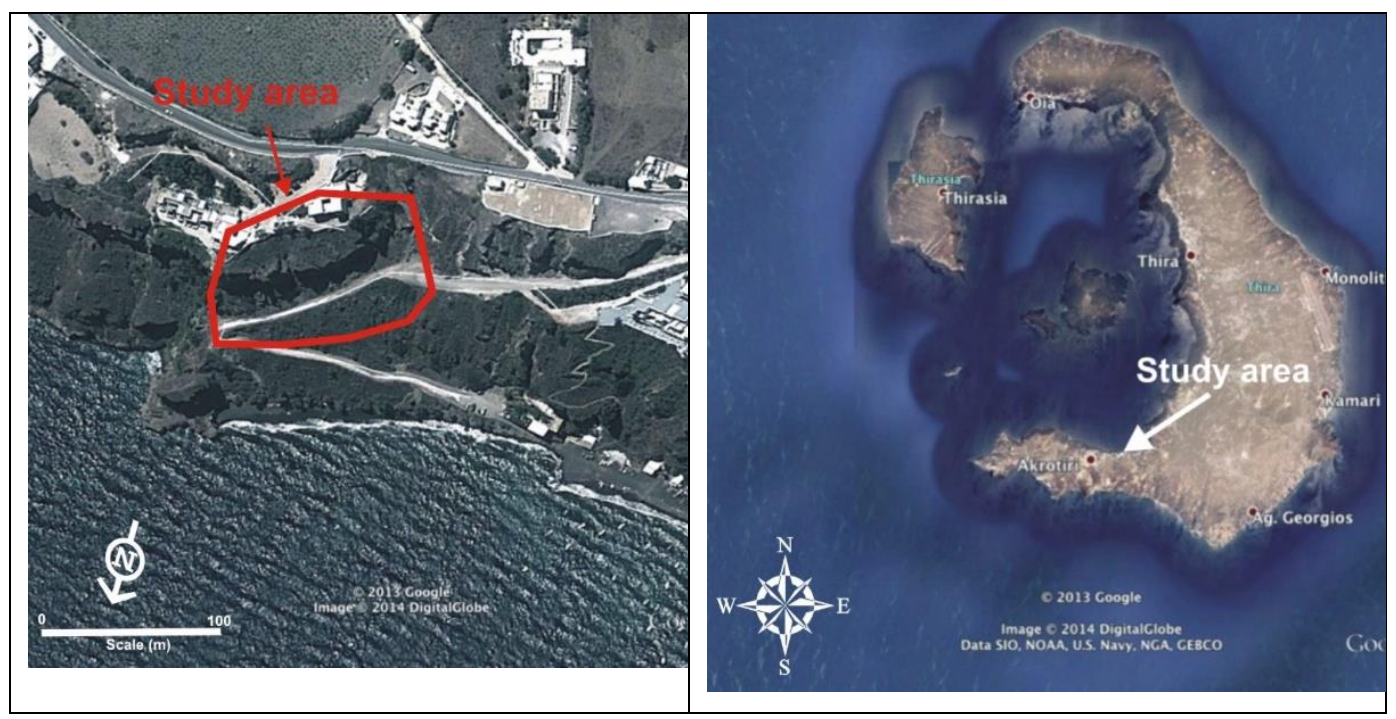

Figure 1 - Location of the volcanic slope in "Apothikes" area, in the southern side of the caldera in Santorini island.

\section{Methodology}

The research was based on the following methodology:

I. Define the engineering geological conceptual model of the area

II. Definition of failure mechanism

III. Segmentation of all the unstable rock blocks and slope zonation according to its instability hazards

IV. Selection of critical parameters and method of stability analysis

V. Stability analysis

VI. Support measures proposal 


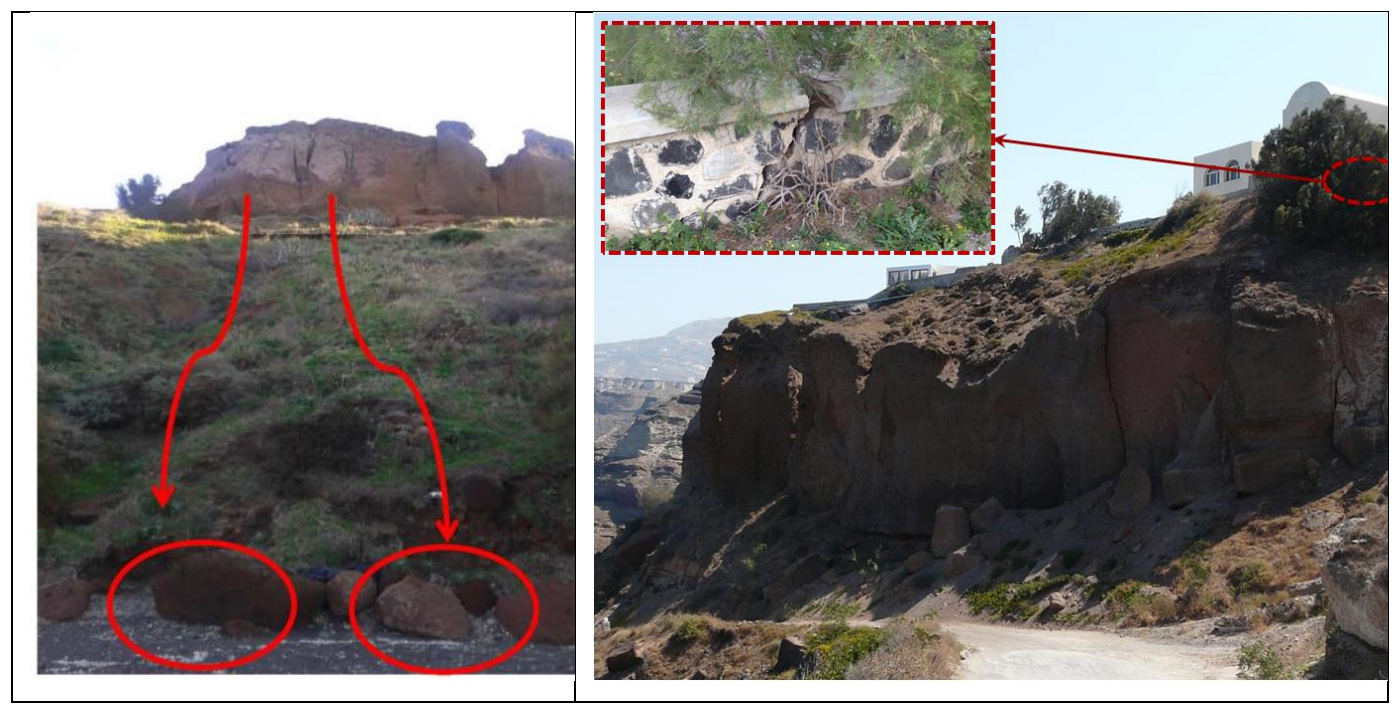

Figure 2 - Blocks are likely to propagate downhill up to the sea level, passing twice over the local road and finally reaching the public beach. The rock block detachment may also create significant problems to the adjacent residences.

The use of LiDar (Light Detection and Ranging) laser scanning provides valuable data for the engineering geological zonation of the area and the rock block quantification for the stability analysis. The blocks at the investigated area were analyzed by InnovMetric's software, Polyworks V10.0 which processes LiDar images. The LiDar is a very useful tool for scanning surfaces in the scale of meters or some dozens. Its operation is based on the light detection that emits. The export file consists of a cloud of points (Figure 3 ) and each point has a standard distance from each other. The point cloud simulates the scanning surface. This file is screened at the $3 \mathrm{D}$ environment of the Polyworks software. With these images, we can measure the line parts and the exact angle of the slope as well as the volumes of the fragments that we cannot measure in site. Also, the software provides the possibility to measure the dimensions and the orientation of planes which are easy to determine at a LiDar image.

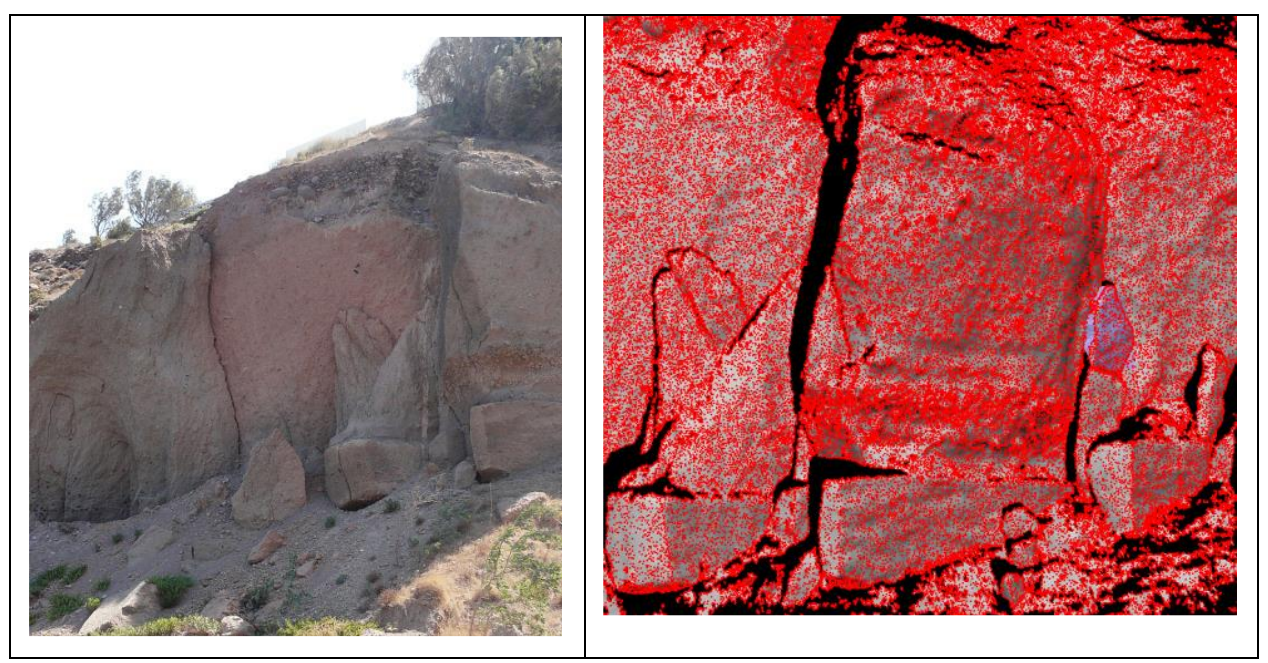

Figure 3 - Point cloud of the area showing some of the unstable rocks and the developed tension cracks in detail. 


\section{Geological setting}

"Apothikes" area is consisted of a successive lava beds alternations. In particular, from the lower to the upper part the general stratigraphy of the area is:

-Ap2: Cape Therma 3 Tuff. Andesitic pyroclastic deposits of the Cape Therma 3 eruption. These deposits occur extensively at this region of the island.

-Rp3: Lower pumice layer which is essentially the peak of the first explosive cycle of the island (Druitt et al. 1999) with a series of rhyodacitic type explosions (Lower pumice 1 and lower pumice 2). At the end of this explosive cycle the first caldera collapse occurs. This formation consists the weak unit that presents high erosion and undermine the overlying ignimbrites.

-Rp6: Cape Riva Tuff which is formatted with materials mostly of dacitic and rhyodacitic composition. The most characteristic formation at this type of volcanic product is an ignimbrite which in many areas has a thickness of $20 \mathrm{~m}$ approx. This formation presents the rock slope instabilities.

-Rp7: Minoan eruption deposits. Contains the three phases of the Minoan eruption which from the lower to the higher part consist from a plinian type explosion pumice overlaid by a surge of phreatomagmatic material and finally on the top from the 3rd phase tuffs containing dacite blocks (Sparks and Wilson, 1990). These pyroclastic sediments are only found in the east side of the road and create some instabilities of falling volcanic bombs due to their weathering.

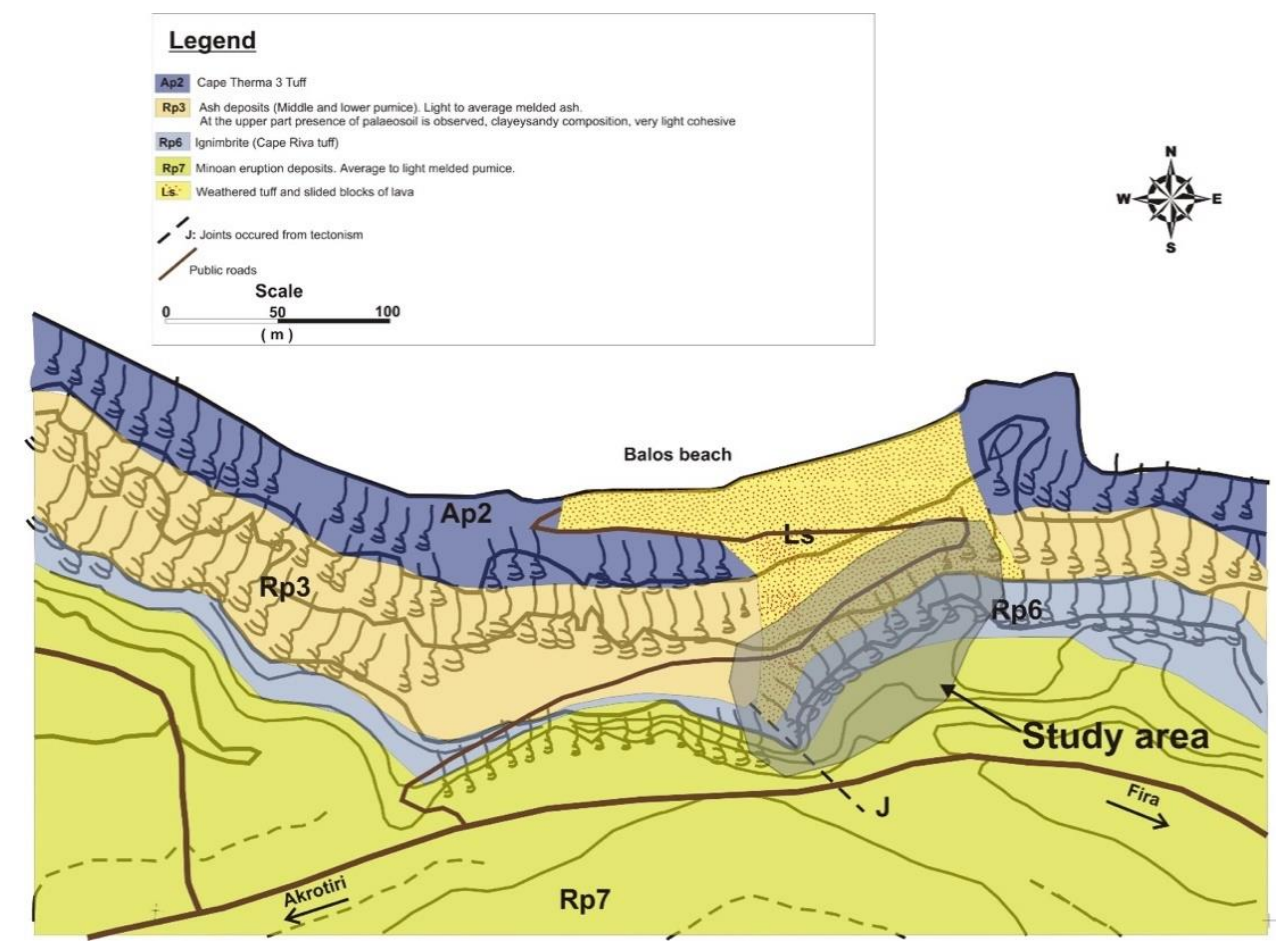

Figure 4 - Geological map of the study area (based on Druitt and Davies, 1995).

\section{Engineering geological assessment}

\subsection{Engineering geological conditions}

The research was based not only to traditional field engineering geological measurements, mapping and laboratory tests, but to terrestrial scanning and detailed geodetic measurements also. All the 
necessary information about the lithology, rock strength, rock mass structure, neotectonic joints, other discontinuities, weathering, erosion and the instability characteristics were evaluated in order to define the engineering geological conceptual model of the area. The laser scanning supported with a focused geodetic detailed surveying provided the geometrical information about the blocks that have failed in the past and all the detached ones or potentially unstable those are going to fail. The detail documentation of the declivity's façade was carried out by using Image Assisted Total Stations, which provide accuracy of $\pm 10^{\text {cc }}$ for the angles and $\pm 3 \mathrm{~mm} \pm 2 \mathrm{ppm}$ for the distances measurement. About one thousand points were measured. The façade (figure 8) and four vertical sections were drawn, where the most important characteristics as the foot of the declivity, major cracks, big rock masses, rock crevices and rock peaks were illustrated. Also for the intergraded survey of the declivity the total scanning with $30 \mathrm{~cm}$ step was carried out. Thus a lot of additional information and individual detail points were provided.

Ignimbrites have high strength but are based on soft and highly erodible tuffs and paleosol. Paleosol is composed of medium dense sandy material with clay. Water infiltrates along the joints of the hard rocks but stops along the impermeable tuffs. Thus, water softens the weak geomaterial, generates pore water pressure abut also builds hydrostatic pressures along the open joints.

Hence, the principal information must be focused on the blocks geometry, resulted from the joint's direction, and the properties of the underlied paleosol and tuff.

In order to quantitatively assess the rock block volume, the joint's geometry and access the hazard for new rock falls, a terrestrial scanning of the area took place. Apart from the LiDar scanning though, the discontinuities were also mapped and measured during a field survey. The mapping of discontinuities was accomplished using traditional methods e.g. a geological compass and a measuring tape. Afterwards, the measured discontinuities planes were plotted as poles on a stereographic projection net and the representative poles at the centres of the concentration zones were assessed. The discontinuities are either cooling joints or originated from tectonism or resulted from stress relief (Figure 6). The acquired data provided by this task were imported in the software Dips from RockScience's and analysed in order to use the outcome for the following step of the slope failure analysis.

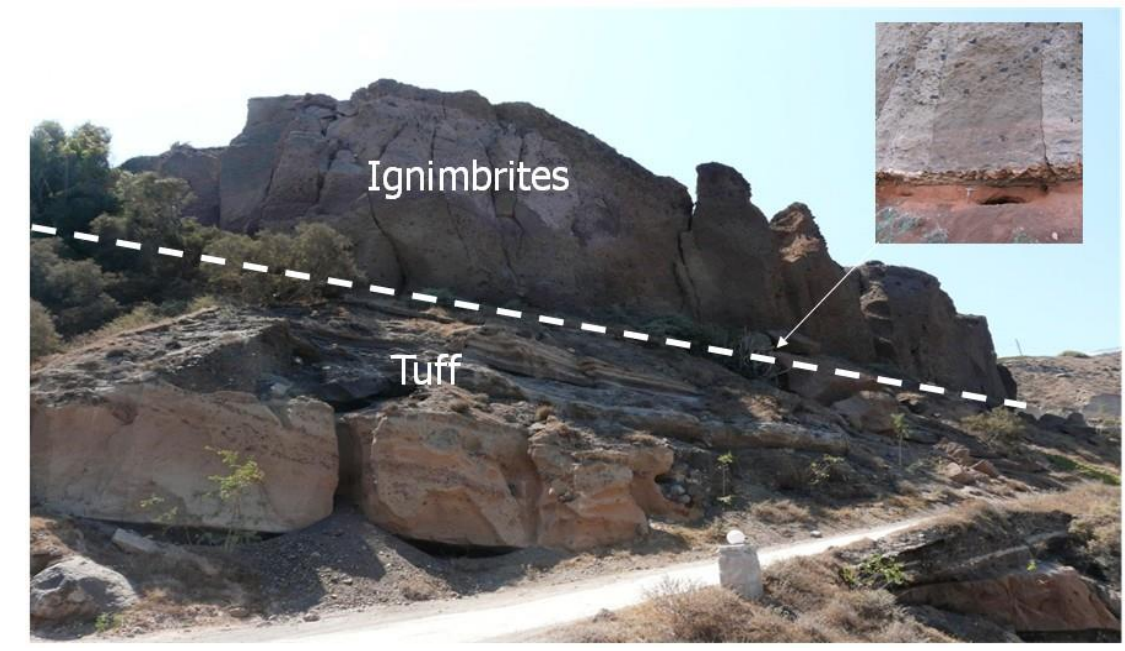

Figure 5 - The differential erosion is caused along the contact of the hard ignimbrite columns and the looser paleosol. This weak surface of erosion generates tensile cracks that are extending with the force of water and wind with time. Picture in frame shows a detailed contact of the ignimbrite body on the paleosoil. 


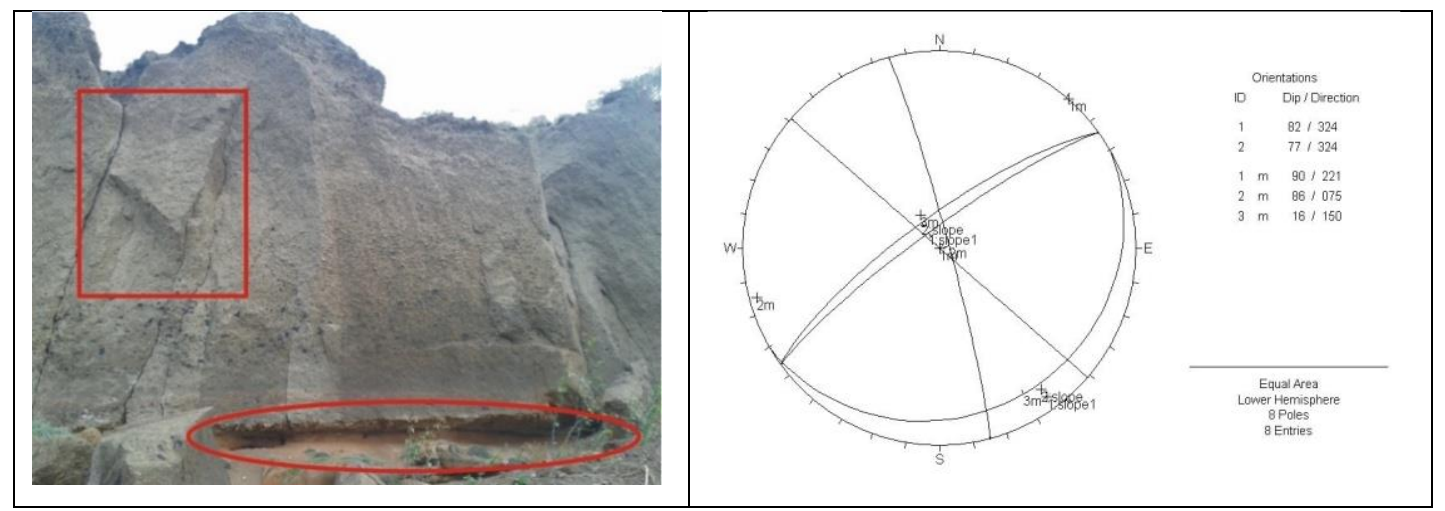

Figure 6 - The paleosol and the underlied tuffs defined as the prime surface of the instability, is illustrated in the ellipse. The discontinuities are either cooling joints or are originated from tectonism or are resulted from stress relief.

The process of the LiDar image of "Apothikes" location had as central axe the determination and measurement of the dimension of blocks. The software provides the possibility to measure the exact volume of a block instead of making assumptions and comparisons to basic shapes. Thereafter, we classified the thickness in order to determine the major class. It was found out that the maximum thickness of the pillars was $5 \mathrm{~m}$ and the $95 \%$ of blocks had thickness below $4 \mathrm{~m}$. Therefore, for our analysis we used the value $4 \mathrm{~m}$ in order to make a realistic model (Figure 7).

Having completed the alignment of the point clouds, a measuring of the dimensions of the unstable rocks was performed. The dimensions of the largest boulders are 10X9m (height X width) while smaller ones are also measured. A segmentation of the rock pillars that are likely to fail were mapped in order to assist the rock fall hazard assessment and the design of the remedial measures (Figure 8).

The hazard of new rock slides is very high, since several unstable rock blocks are present, either already moved or unloaded by recent instabilities. Indeed, instabilities have been recorded in the whole length of the road, several blocks are found along the beach, while wide open joints are present.

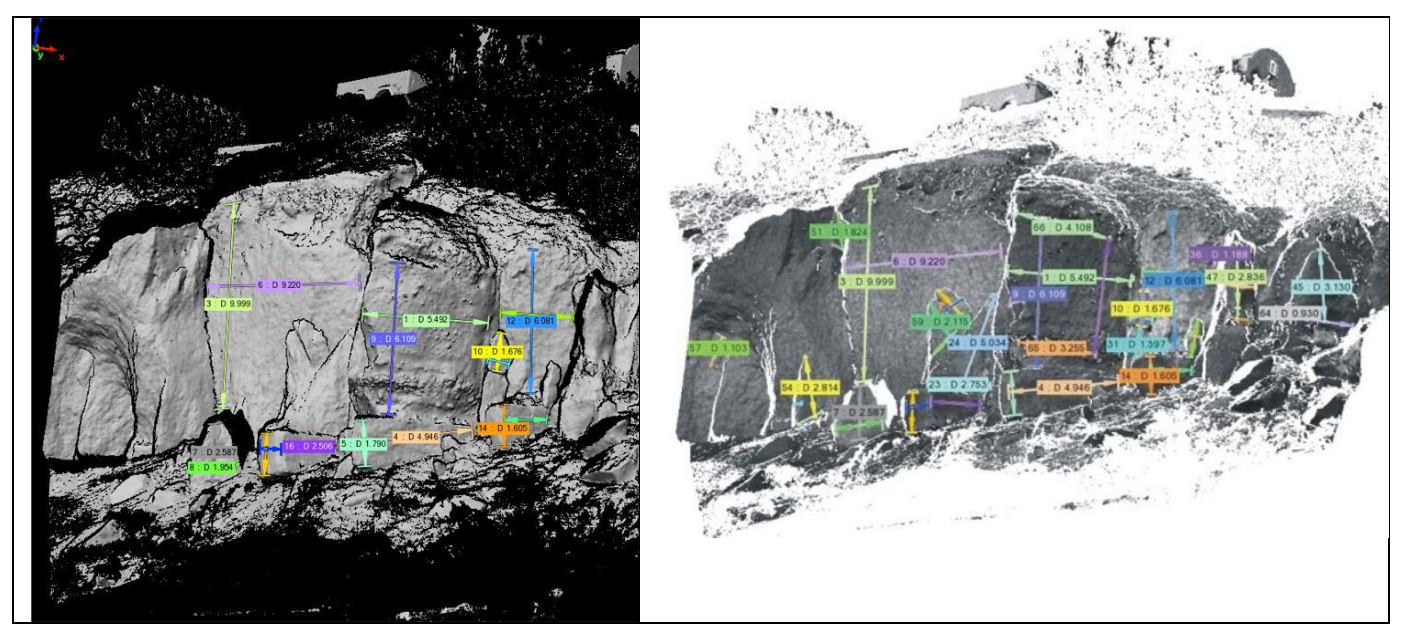

Figure 7 - LiDar image showing the estimation process of dimension of the unstable or fallen blocks (right). 


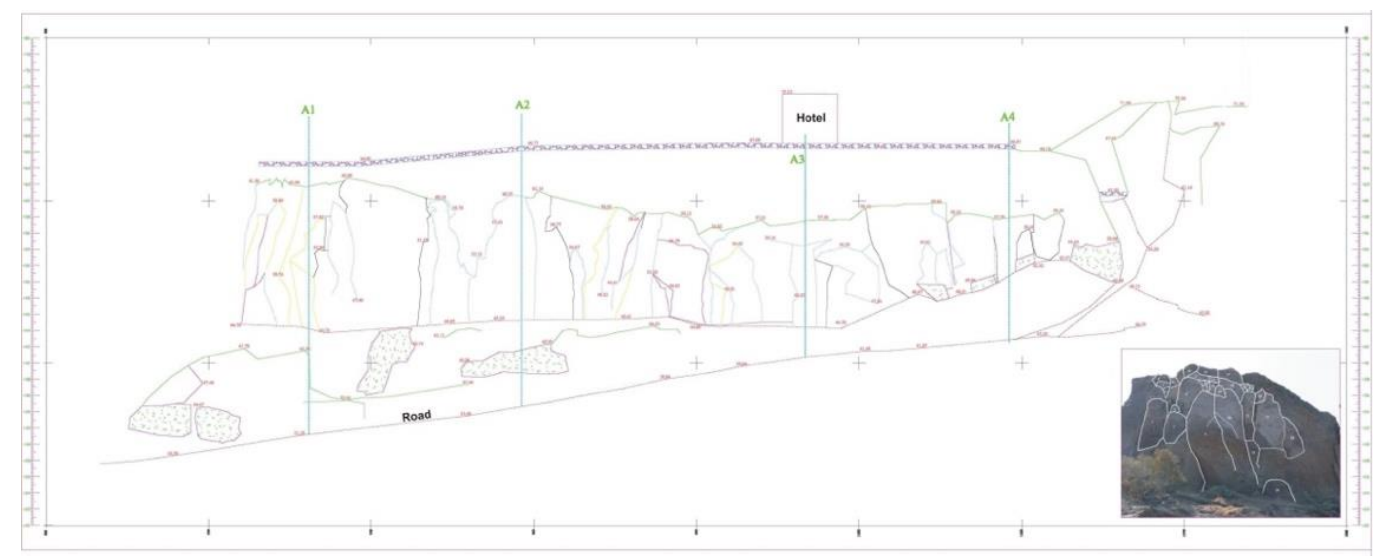

Figure 8 - The façade depicting all the unstable blocks along the studied area.

\subsection{Failure mechanism}

The main failure mode consists of rock pillar detachment followed by toppling or planar sliding failure, which result to their fragmentation. As the morphology is steep, blocks are likely to propagate downhill until sea level, passing three times over the local road and finally through the public beach. It has been concluded that the slopes are likely to collapse due to differential weathering. The differential erosion is caused along the contact of the hard ignimbrite and the looser paleosol. This weak surface of erosion generates tensile cracks that extend with the force of water and wind with time. Thus, erosion is then accelerated. These tension cracks combined with other transverse joints, possibly connected with tectonism, creates columns of blocks of significant volume. As an outcome overhanging blocks of the hardest rock failed under self-weight, sliding along the weak underlied soil and fissure water pressure. The blocks that fall reveal new and fresh surfaces and as a result, the laterally blocks exhibit a lack of confining stress. Therefore, new cracks begin to appear and the same process accelerates. An engineering geological conceptual model of the studied area is presented in Figure 9.

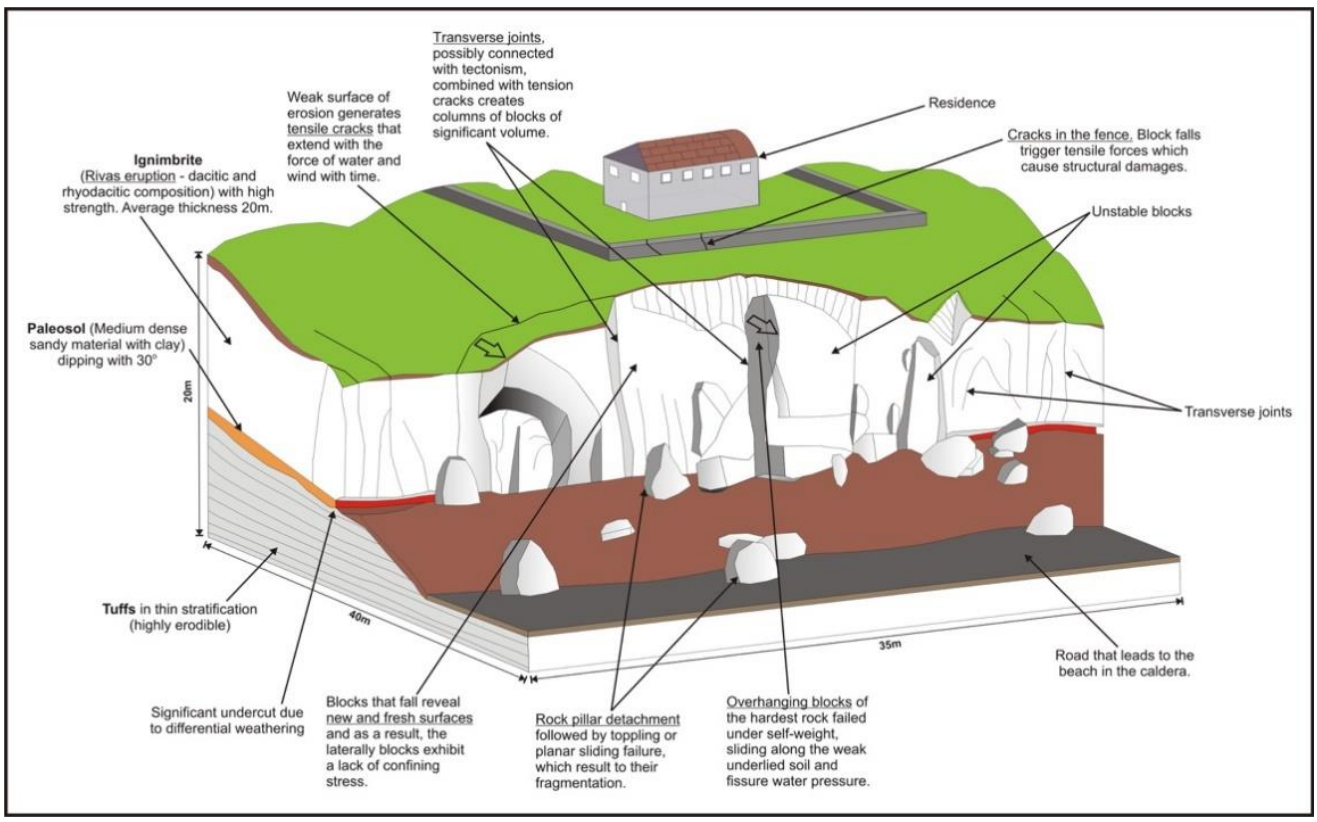

Figure 9 - An engineering geological conceptual model of the studied area. 


\section{Stability analysis}

In general, toppling is typically preceded by a slow displacement where the rock weight is gradually redistributed to the toe of the column. For the slope in question, this displacement coincides to planar sliding. Therefore, analyses were performed using RocPlane software from RockScience's suite, assuming that planar sliding occurs on the interface of the two materials. Initially, the model was validated reproducing the conditions causing the recent failures and afterwards the remedial measures were designed according to EC7.

The model consists of a $20 \mathrm{~m}$ height and slightly overhanging slope $\left(92^{\circ}\right)$. The planar surface was simulated with an exaggerated inclination of $30^{\circ}$, since sings of prior failures indicated that the critical plane passes through the weak underlying layer. Material properties were determined by field and laboratory tests, resulting to the equivalent Mohr-Coulomb parameters that were used for the analyses $\left(c=5 \mathrm{kPa}\right.$ and $\left.\varphi=30^{\circ}\right)$. Vertical discontinuities (persistent throughout the whole slope's height; therefore, filled with water) were simulated $4 \mathrm{~m}$ behind the crest. In order to design the full face nailing pattern, static and pseudo-dynamic analyses were conducted for various water heights within the discontinuities.

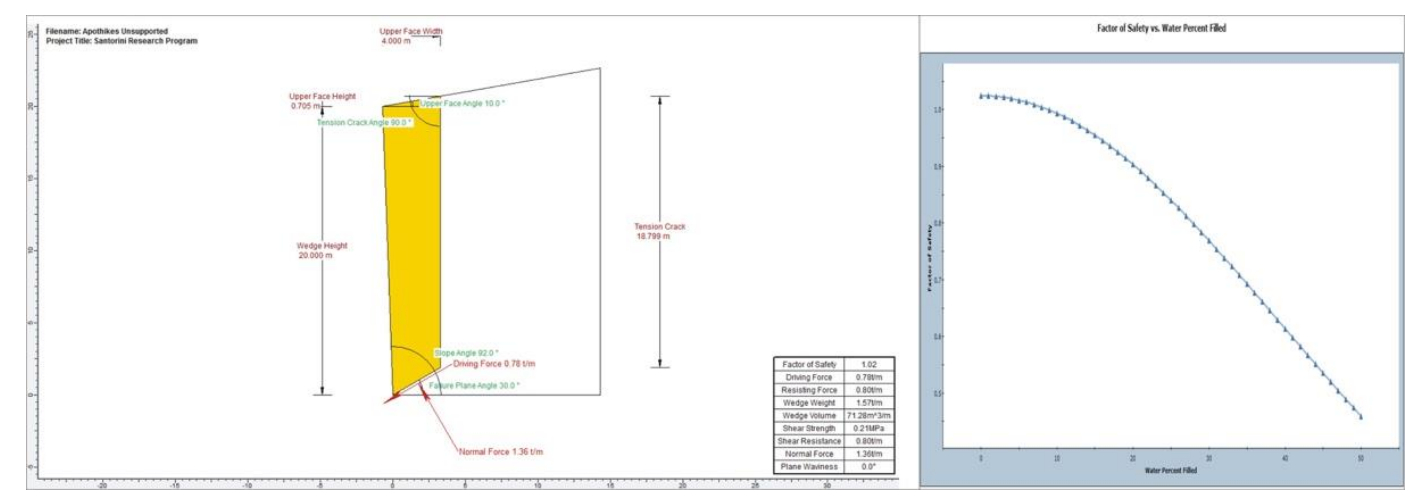

Figure 10 - Sliding analysis with RocPlane software from RockScience's suite shows that safety factor (F) is 1.02 (left). Diagram Factor of Safety-Water Percent Filled, shows that safety factor (F) drops below 1.0 with a small percentage of water (right).

\section{Remedial measures}

In order to prevent failure and the accompanied consequences, various mitigation methods were examined based on the site's geological and geotechnical conditions, cost, local architecture restrictions and constructability. The principle of the proposed measures are: a. Extensive mechanical scaling in order to create a safe working environment and slope free of tension cracks; b. Nailing with fully bonded anchors $(\mathrm{d}=25 \mathrm{~mm}, \mathrm{l}=10 \mathrm{~m})$ on a $2 \times 2$ pattern and c. Steel nets, in case of local poor rockmass conditions, that will be anchored to the nails and lashed by transversal wire ropes.

Rock bolting is favoured since the rockmass is massive and intact strength is sufficiently high, therefore the anchoring of partially detached pillars can treat toppling. However, this is applicable only when existing discontinuities present relatively small aperture, since bolting efficiency is severely reduced when aperture is increased.

In that case, cable lashing the rock pillars forms an alternate solution. A key design consideration is the ability to wrap the lashes tightly around the pillars. If the surface is flat, the cable requires extended block displacement in order to engage their tensile strength (Turner \& Schuster, 2013)). However, embracing the pillars is favoured by the morphology of slope in some occasions, containing the required anchoring force. Due to slope's extended height $(\mathrm{h}>15 \mathrm{~m})$ instead of the typical lashes, a pre-stressed face net (similar to the spider system provided by Geobrugg or similar 
from others) becomes extremely effective. However, this solution requires the ability of the surrounding rockmass to bear the anchoring forces, which is not always the case in the slope since various detached rock pillars are neighbouring to each other. The latter, makes mechanical scaling of potentially unstable pillars unavoidable. Due to the ongoing relaxation and weathering, scaling improvements are temporary and slope must be periodically inspected and when necessary reworked.

In general, failure susceptibility is increased by surficial and groundwater flow (Hoek and Bray, 1981). Moreover, the differential erosion of the underlying weak layer that consists slope's toe, is likely to accentuate due to groundwater flow. Therefore, controlling water in the rockmass become crucial. As the discontinuities are mostly charged with water from the crest and the overlying structures, a ditch behind the crest of the slopes is likely to adequately prevent from seepage, reducing failure susceptibility.

Ongoing weathering of the weak material at slope's toe must also be contained, since it forms the crucial toppling or planar mechanism. Weathering and erosion of the slope's toe are primary attributed to the coastal environment. In order to control them, two different techniques were examined, as discussed hereafter. The weak layer can be sealed covering the slope surface with specialized polyesteric or epoxic mixtures. They are applied similarly to shotcrete, however the result is harmonized with the environment since a nearly transparent crust is produced, in contrary to shotcrete. The second approach is to construct a retaining structure at slope's toe that will be filled with granular material. The height of the fill must be adequate to full cover the weak layer, isolating it from the shore environment. In the same time this structure combines the capacities of a ditch and a rigid barrier, being able to mitigate small-sized rockfalls. However, this approach arise constructability issues and an overall significant cost.

Construction must be completed within a short time period, in order to avoid further occurrence of tension cracks. Prior to any activity, a detailed monitoring system must be installed in order to further examine slope's response and following construction to evaluate the efficiency of remedial measures.

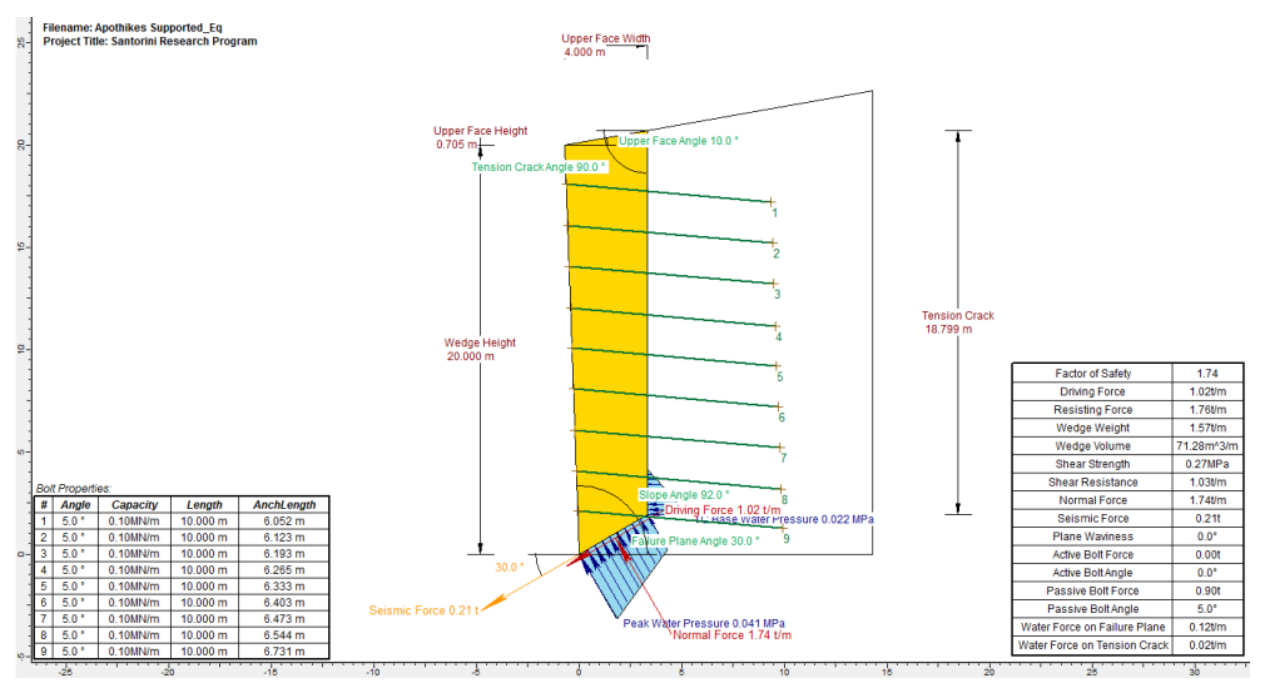

Figure 11 - Sliding analysis with RocPlane software from RockScience's suite, after the implementation of the remedial measures.

\section{Discussion}

The present work presents how the use of terrestrial laser scanning can assist towards the engineering geological assessment against slope stability. Apart from the LiDar scanning the research was also based on traditional field engineering geological measurements, mapping and laboratory tests. The use of LiDar (Light Detection and Ranging) laser scanning and focused surveying diagrams 
provided valuable data for the engineering geological zonation of the area and the rock block quantification for stability analysis. The rock fall hazard is very high, since several unstable rock blocks are present, either already moved or unloaded by recent instabilities. Indeed, instabilities have been recorded in the whole length of the road, several blocks are found along the beach, while wide open joints are present.

The main failure mode consists of rock pillar detachment followed by toppling or planar sliding failure, which result to their fragmentation. The differential erosion is caused along the contact of the hard ignimbrite columns and the looser paleosol. In general, toppling is typically preceded by a slow displacement where the rock weight is gradually redistributed to the toe of the column. For the slope studied, this displacement coincides to planar sliding. Slope stability analyses were performed based on the engineering geological conceptual model of the area and the block geometry that has been measured and mapped.

In order to prevent failure and the accompanied consequences, various mitigation methods were examined based on the site's geological and geotechnical conditions, cost, local architecture restrictions and constructability. The principle proposed measures are: a. Extensive mechanical scaling in order to create a safe working environment and slope free of tension cracks; $b$. Nailing with fully bonded anchors on a $2 \times 2$ pattern and c. Steel nets, in case of the presence of poor localized rockmass conditions, that will be anchored to the nails and lashed by transversal wire ropes.

\section{Acknowledgments}

The authors would like to thank the Municipality of Thira for funding this study.

\section{References}

Apuani T., Corazzato, C., Cancelli A. and Tibaldi, A., 2005. Physical and mechanical properties of rock masses at Stromboli: a dataset for volcano instability evaluation, Bull. Eng. Geol. Env., 64, 419-431.

Hoek, E. and Bray, J.D., 1981. Rock slope engineering, CRC Press.

Druitt, T.H., Mellors, R.A., Pyle, D.M. and Sparks, R.S.J., 1989. Explosive volcanism on Santorini, Greece, Geol. Mag., 126, 95-126.

Druitt, T.H. and Davies, M.A., 1995. Geological Map of the Santorini Islands, Scale 1:2000.

Druitt, T.H., Edwards, L., Mellors, R.M., Pyle, D.M., Sparks, R.S.J., Lanphere, M., Davies, M. and Barriero, B., 1999. Santorini Volcano, Geological Society Memoir, No 19, 165 pp.

Huijsmans, J.P.P., Barton, M. and Salters, V.J.M., 1988. Geochemistry and evolution of the calcalkaline volcanic complex of Santorini, Aegean Sea, Greece, Volcanology and Gothermal Research, 34, 283-306.

Moon, V., 1993. Geotechnical characteristics of ignimbrite: A soft pyroclastic rock type, Engineering Geology, 35, 33-48.

Potro, P. and Hürlimann, H., 2008. Geotechnical classification and characterisation of materials for stability analyses of large volcanic slopes, Engineering Geology, 98, 1-17.

Sparks, R.S.J. and Wilson, C.J.N., 1990. The Minoan deposits: a review of their characteristics and interpretation, In: Hardy, D.A., eds., Thera and the Egean World III, 2 The Thera Foundation, London, 89-99.

Turner, A.K. and Schuster, R.L., 2012. Rockfall: characterization and control. Transport Research Board of the National academies. 